\title{
A QUESTÃo DA LEGITIMIDADE DA CLÁUSULA DE INDEXAÇÃO DE CONTRATO PELA VARIAÇĀO DE MOEDA ESTRANGEIRA
}

\author{
Carlos Alberto Bittar \\ Professor Associado do Departamento de Direito Civil \\ da Faculdade de Direito da Universidade de São Paulo \\ Advogado militante
}

\begin{abstract}
Resumo:
Discute-se, entre nós, a respeito da validade de cláusula de indexação de contrato do dolar turismo, em razão da proibição legal de estipulação em moeda estrangeira. Entende-se, no entanto, válida a previsão, salvo explícita vedação legal, pois constitui mero mecanismo de atualização de valor, que a inflação justifica no equilíbrio contratual.
\end{abstract}

Abstract:

In Brazil, payments in foreign courrency can not be stablished by contrats. However, provisions based on the change of value of dolar turismo have to be considered valid, unless expressly prohibitted by law, for they are just money - correcting.

Sumário:

Contrato: cláusula de indexação pela variação do denominado dólar turismo Ajuste expresso feito pelas partes Inexistência de óbice legal, que se restringe à estipulação de pagamento em moeda estrangeira (Dec.-lei 857, de 11.9.69) Contrato de trato sucessivo, em que a cláusula se funda na autonomia da vontade e realizado de boa-fé Impossibilidade superveniente de alegação de ilegitimidade, que feriria o princípio da boa-fé, subordinando o devedor aos sancionamentos próprios.

1. Discute-se, na doutrina, a respeito da possibilidade de utilização, em contrato, de indexador baseado na oscilação de moeda estrangeira, diante da legislação vigente, bem como da respectiva força vinculatória. Cuida-se de definir a legitimidade, ou não, de cláusula de correção, em contrato de trato sucessivo, estipulada com base na variação de cotação do denominado dólar turismo (ou outro), frente à conhecida proibição de pagamento em moeda estrangeira para 
obrigação exigível no país, assim como de seu alcance posterior, uma vez contratada (Dec.-lei 857/69).

2. Afigura-se-nos, de início, de fácil alcance a distinção entre estipulação em moeda estrangeira, que pode recusar o curso legal do cruzeiro, e indexação de débito com base em oscilações de cotações do dólar norteamericano, que em nada atinge o fluxo natural da moeda nacional.

3. É que a vedação legal, que se inclui na linha da proibição de cláusula-ouro em contrato está relacionada à necessidade de garantir-se a fluência da moeda do país. Trata-se, assim, de norma assecuratória de exclusividade à moeda nacional, na defesa da respectiva economia.

Diverso é o sentido da cláusula de indexação, que procura preservar o poder de troca da moeda diante da constante inflação que tem atingido nossa economia. Ora, nesse passo, essa a cotação funciona como mero indicador na atualização do valor-base previsto no contrato. Não constitui, pois, estipulação em moeda estrangeira, mas sim simples mecanismo de determinação do valor real da obrigação de pagamento, como qualquer outro índice, diante do extenso elenco ora existente, face à complexidade alcançada no mundo negocial.

4. Entendemos, assim, desde logo, perfeitamente legítima a sua adoção em ajuste firmado para execução no país, pois em nada se contrapõe à legislação mencionada, dentro da autonomia reconhecida às partes na definição do conteúdo de contratos de seu interesse. Ademais, com nenhuma outra norma legal conflita essa disposição, permitindo, ao revés, dentro do universo dos esquemas de proteção do poder aquisitivo da moeda, a adequação do valor aos efeitos negativos decorrentes da inflação.

5. Parece-nos evidente, de outro lado, que, sempre que exista regra legal vedatória, nula será a estipulação com base no índice mencionado, como acontece, por exemplo, na legislação sobre inquilinato, em que está proibida, por expresso, tal previsão (Lei 8.245, de 18.10.91, arts. 17 e 85).

Fica, nesse caso, inviabilizada a fórmula, em razão da disposição de ordem pública contrária. 
6. Não havendo, no entanto, comando explícito em caráter negatório, prospera a autonomia das partes na contratação e, uma vez reduzida a escrito a cláusula indexatória, passa a valer em suas relações, não admitindo posterior recusa.

Aliás, a adoção da referida técnica retrata a preocupação, presente em qualquer contratação de vulto realizada no país, com a perda do poder de compra da moeda, face à insistente inflação apurada a cada época e a cada mês, de uns tempos a esta parte. A necessidade de segurança, que deflui, de um lado, do enfraquecimento da moeda nacional e da estabilidade da moeda norte-americana e do esquema comparativo que permite é, ademais, ponto nevrálgico em contratos de maior vulto.

7. É, pois, na linha da correção monetária de valores contratuais que as partes têm obtido resguardo, em razão da constante inflação que se verifica em nossa economia, desequilibrando situações não acobertadas por cláusulas próprias de atualização.

8. Essa é a tônica nos contratos de prazo ou em obrigações outras em que o fator tempo interfere, razão pela qual, hodiernamente, todos os ajustes prevêem alguma modalidade de reajuste compatível. Em outras hipóteses, a indexação decorre de legislação específica, não se observando, pois, a regra, antes geral, da prevalência do nominalismo monetário.

Diante da consciência da futura inflação, inserem-se as cláusulas de correção, garantindo-se que se preserve o valor da moeda contratual, atualmente sob plena acolhida da doutrina.

9. Enfocando a temática da indexação do contrato por meio de cláusulas de reajuste, em suas lições sobre direito civil, realça Orlando Gomes os meios técnicos para correção dos efeitos negativos da depreciação monetária, lembrando as cláusulas de reajustes e, depois de ressalvar a proibição legal de previsão de cláusula-ouro, escreve, verbis:

"Para fugir a essa proibição, as partes começaram a inserir, nos contratos, cláusulas pelas quais a quantia a ser paga é fixada em função das variações de determinado índice econômico, como, por exemplo, o 
valor-ouro, divisas estrangeiras e valor divisas) já que não proibidas e por não contrariarem as disposições legais sobre o curso forçado do cruzeiro papel;

2. A validade da cláusula de escala móvel não depende nem da personalidade dos contratantes, nem do índice escolhido. Somente é inválida a cláusula de escala móvel quando seus efeitos forem contrários a uma lei de ordem pública, como aquela que congela aluguéis ...;

3. Os tribunais brasileiros reconhecem as modificações do poder aquisitivo da moeda e procuram corrigir o desequilibrio entre as prestaçōes das partes causado por este motivo, como acontece em matéria de desapropriação ..." (A cláusula de escala móvel, São Paulo, Max Limonad, 1956, p. 132-133).

Concluindo, depois, suas idéias sobre o tema, ressalta que:

"Na luta pela adoção da cláusula de escala móvel, militam juntas a segurança e a justiça, para garantir a cada um o que é seu hoje e o que será seu amanhã, para dar ao indice o papel que a moeda já não pode exercer de ponte entre o presente e o futuro ..." (Ibid., p. 169).

12. Pode-se, aliás, assentar que sempre a doutrina se posicionou a favor dessas cláusulas, diante da necessidade de se resguardar o equilibrio no contrato, afetado por depreciações ocorridas com o valor da moeda circulante.

Em nosso país, é mesmo tranqüilo e pacífico o entendimento da doutrina atual (v. a respeito, dentre outros autores, Washigton de Barros Monteiro, Curso de direito civil, São Paulo, Saraiva, 1977, v. 2, p. 74; Maria Helena Diniz, Curso de direito civil: teoria das obrigações, $3^{\text {a }}$ ed., São Paulo, Saraiva, 1987, v. 2, p. 83 e ss., em que analisa as cláusulas de escala móvel e de correção monetária, admitindo expressamente a pactuação para evitar-se o 
aviltamento ou a desvalorização da moeda, respeitadas as normas da ordem pública).

13. De nossa parte, salientamos em volume de nosso curso de direito civil, referindo-nos à obrigação pecuniária:

"Mas a obrigação pecuniária deve ser originariamente estipulada como tal, podendo as partes, no contrato, prever as formas de correção possíveis, por meio de revisão de valor, conforme preço do bem ou indice geral do custo de vida (escala móvel), ou por indices oficiais (correção monetária), mantendo-se as correspondências nas prestações. Há também reajustamentos previstos em lei, em vários setores (como na locação, na venda a prestação, de empréstimo, de financiamento, etc). A correçāo monetária, que se destina a atualizar $o$ valor do dinheiro, mantendo seu poder de compra, pode, assim, ser contratual ou decorrer de lei, ficando a respectiva indexação, de regra, sob a vontade das partes, respeitados sempre os limites que a ordem jurídica impõe..." (Direito das obrigações, Rio, Forense Universitária, 1990, p. 53).

14. Posiciona-se a jurisprudência, aliás, depois de certa vacilação inicial, francamente favorável a tais cláusulas, de vez que a correção monetária se integrou, em definitivo, em nossa cultura econômica. Inúmeros são os julgados em que se admite a cláusula de reajuste e a conseqüente correção monetária do valor da obrigação e em figuras contratuais as mais diversas, mesmo quando referenciadas a títulos de crédito e inclusive com notas promissórias.

Do extenso elenco de decisões que detectamos, destacamos acórdãos do Supremo Tribunal inseridos em: RTJ 49/89, 53/378, 56/858, 57/883, 59/848, 61/104, 65/157, 67/769, 69/736, 81/42, 101/765, 120/451, dentre vários outros. Ademais, nas diferentes instâncias tem prosperado a mesma orientação e com a latitude exposta (dentre inúmeros outros, v. acórdãos em: RJTJESP 81/42, 
98/71; JTA 82/430, 88/111, 92/13, 93/62, 94/49, 108/108, 112/64; RT 571/105, $579 / 35,614 / 49$ e $637 / 115)$.

Realce-se, a propósito, que os tribunais enfrentaram, com firmeza, sob as diretrizes traçadas pela doutrina, tanto questões referentes à correção em si, quanto relativas à indexação com base em variação de moeda estrangeira, declarando a sua plena adequação ao sistema legal vigente (v. em especial as decisões inseridas em RJTJESP 81/42 e 98/71; JTA 92/13 e 112/64; RT 571/105 e 614/49; e JSTF 93/130), inclusive em questões que envolviam títulos de crédito (v. JTA 112/64 e RT 637/115) e interpretação do alcance da proibição da cláusula-ouro (RT 460/160).

15. Prevalecem as mesmas diretrizes no direito comparado, em que as cláusulas de reajuste recebem nomes diferentes, tais como: cláusulas de salvaguarda, de estabilização, de garantia e de premunição.

16. Discorrendo sobre o tema, com a profundidade característica, acentua Luiz Diez-Picazo:

"El nominalismo conduce, cuando las oscilaciones del valor intrínseco o del poder aquisitivo de las monedas o del dinero son muy grandes, a unas consecuencias evidentemente injustas, que sólo por razones de seguridad jurídica pueden imponerse y que adquiren una extraordinaria gravedad cuando tales oscilaciones en el valor del dinero conducen en la práctica a una desaparición de este valor. Ello hace que haya habido que buscar remedios para evitar tales consecuencias y que se hayan intentado articular medidas de conección de la aplicación rigurosa del sistema nominalista".

Adiante, depois de mencionar o critério da lei, cuida da cláusula de natureza convencional ou negocial, frisando:

"A través de ellos, son los mismos interesados quienes, por medio de los pactos y disposiciones que 
establecen, tratan de evitar en sus mutuas relaciones las consecuencias que para ellos llevaria aparejada la normativa general en materia monetaria. En terminos generales a todo este tipo de pactos o disposiciones se le puede llamar 'cláusulas de estabilización', en la medida que tienen por objeto estabilizar entre las equilibrio de las prestaciones"

Em outro passo, pontifica:

"Les llamadas cláusulas de estabilización pueden ser de dos tipos completamente distintos:

19. Cabe, en primer lugar, que las partes traten de sustituir en sus negocios y transaciones la valuta ou moneda nacional por otro signo diferente. Por exemplo: el oro y la plata, una moneda extranjera, etc.

$2^{2}$. El segundo tipo posible de cláusulas estabilizadoras es el de aquellas disposiciones negociales por medio de las cuales las partes, al establecer o fijar una prestación pecuniaria, cujo cumplimiento queda diferido para un momento posterior, determinan la relación que existe entre la suma de dinero objeto del pacto y el precio o valor de una determinada mercancía o de unos determinados indices, quedando obligados a reajustar la suma dineraria debida, de acordo com aquella proporción, para el caso de que el dinero experimente con el curso del tiempo alguna variación. Aqui non se trata de sustituir el dinero o la valuta nacional como medio de pago, sino de establecer una equivalencia e imponer convencionalmente un posterior reajuste".

Por fim, lembrando Roca Sastre, conclui o citado autor:

"Las cláusulas de estabilización tratan de lograr que la prestación consista realmente en una cantitad de 
dinero que represente en el momento del pago el mismo valor que dicha suma tenía en el momento de constituirse la obligación, en relación con su poder aquisitivo" (Fundamentos del derecho civil patrimonial, Madrid, Tecnos, 1972, p. 459-460).

17. Do mesmo sentir é o monografista Antonio Pinto Monteiro que, após realçar o caráter de previsão contra riscos da depreciação da moeda que as cláusulas possuem, assinala:

"Entre nós as cláusulas estabilizadoras são permitidas. Solução de aplaudir, visto que permitem a defesa antecipada das partes contra o risco de depreciaçāo da moeda, fomentam um equilíbrio equitativo das prestações contratuais, evitam a paralisação do tráfego econômico e permitem a defesa das categorias sociais mais desfavorecidas, principais vítimas da inflação" (Inflação e direito civil, Coimbra, Almedina, 1984, p. 20).

18. Nessa linha encontram-se, aliás, todos os autores que, no exterior, têm versado o tema, de que enumeramos: Jean Wasilkowski, que mostra a evolução ocorrida a respeito na jurisprudência (Contribution à l'étude du problème de la valorization, Paris, Sirey, 1929, p. 21 e ss. e 37 e ss.) e George L. Pierre-François, que acentua que, diante da inflação, a moeda perde o caráter de instrumento de intermediação das trocas; daí, a premunição das partes contra esse fenômeno (La notion de dette de valeur en droit civil: essai d'une théorie, Paris, Librairie Générale, 1975, p. 96 e ss. e 103 e ss., em que, ademais, realiza ampla discussão sobre o alcance das cláusulas e o labor da jurisprudência em inúmeras situações práticas).

Aliás, a doutrina estrangeira vem, de longa data, cuidando da matéria e refletindo a preocupação dos juristas diante de efeitos negativos da inflação em situações contratuais, e em outras questões em que se operaram câmbios sensíveis na vida social (v. Georges Ripert, La règle morale dans les obligations civiles, Paris, Librairie Générale, 1949, p. 160 e ss.; René Savatier, Les 
métamorphoses économiques et sociales du droit civil d'aujourd'hui, Paris, Dalloz, 1964, p. 48 e ss., dentre outros autores).

19. Foi exatamente diante do trabalho da doutrina que a jurisprudência conseguiu, de há muito, estabelecer a distinção entre cláusulaouro e cláusula de reajuste, a primeira vedada e a segunda acolhida pela ordem jurídica (como nos textos da Rivista di Diritto Commerciale, 1923, p. 589 e ss.; 1932, p. 210 e ss.; 1933, p. 56 e ss.; 1951, p. 338 e ss., dentre outros tantos).

Assentou-se, com isso, a distinção entre a efetividade da contratação em ouro ou em moeda estrangeira (vedada) e a simples correlação com o dólar, ou outra moeda, como elemento indexador (admitida).

20. Encontra-se, ademais, perfeitamente ajustado à hipótese vertente, $o$ indexador referido, pois inexistindo óbice legal à matéria, passa ela a situar-se no domínio da autonomia reservada às partes para a regulação de seus interesses.

Com efeito, no universo fático, ações existem que se situam em plano atingível pela simples vontade das partes, diante, precisamente, da ausência de vedação no ordenamento legal.

Nesse sentido, as relações contratuais são firmadas e dominadas por um princípio básico, o da autonomia da vontade, consoante a qual podem os interessados dispor, em forma de regras, as ações que lhes parecem convenientes na busca de efeitos permitidos, nos limites próprios a cada situação.

21. Disserta, a propósito, Luigi Cariota Ferrara:

"Il negozio giuridico, in quanto costituisce uno dei mezzi per l'auto-regolamento dei propri interessi, in quanto è mezzo de attuazione del dominio della volontà nella sfera giuridica propria del soggeto, è il precipuo strumento dell'autonomia privata.

Tale regolamento è riconoscinto dal diritto. Anzi il riconoscimento del valore dei contratti, del testamento, ecco, in breve dei negozi giuridici, da parte 
dell'ordinamento, è miglior segno che l'ordinamento stesso ammette l'autonomia" (Il negozio giuridico, Napoli, Morano, s.d., p. 54-55).

22. A respeito desse princípio cardeal, escrevemos, em outro livro do referido curso:

"O princípio nuclear do universo contratual é o da autonomia da vontade, consoante o qual as partes, em razâo da liberdade natural, podem buscar livremente efeitos tutelados na ordem jurídica, através de declaraçōes convergentes de vontade, regulando, em plano de igualdade, suas relações.

Significa, pois, o poder de auto-regulamentação de interesses privados, diante dos pressupostos de liberdade $e$ de igualdade entre os titulares de direitos, por meio do qual as partes livremente se obrigam em torno de determinado negócio ou deixam de vincular-se, fixando as condições para a regência de seu relacionamento.

As partes têm a faculdade de contratar, ou não (liberdade contratual, ou de contratar), definindo regras para a respectiva vinculação (liberdade de escolher o contrato, de definir o seu conteúdo e a forma), dentro do âmbito de negócios suscetiveis de disciplinação pela vontade (Direito dos contratos e dos atos unilaterais, Rio, Forense Universitária, 1990, p. 34).

23. Essa é, aliás, a doutrina universal (v. René Démogue, Traité des obligations, Paris, Arthur Rousseau, t. 2, p. 129 e ss.), que encontra plena aplicação na prática, sempre que as partes, espontaneamente, elegem determinado indexador para suas relações econômicas, frisando, no contrato, esse caráter.

Diversa é a solução, quando em moeda estrangeira se perfaz o contrato, que então incide na norma vedatória de estipulação em valores monetários alienígenos. 
24. Configura-se, assim, na espécie, correção monetária contratada, exatamente para a preservação da real expressão da moeda e, não, contratação em moeda estrangeira, esta sim vedada pela lei.

Não é isso que prescreve o diploma legal restritivo de estipulação em moeda estrangeira, que se preocupa, exclusivamente, com clausulamentos que importem em restrição ao curso normal da moeda nacional.

25. Com efeito, debatendo, em toda a sua extensão, a temática da admissão, ou não, de moeda estrangeira na área cambial, o monografista Mauro Brandão Lopes assim se pronuncia:

"Em face da necessidade de garantir o curso legal do cruzeiro, declaram-se nulos todos os contratos que restrinjam ou recusem o curso legal do cruzeiro, todos os títulos que restrinjam ou recusem o curso legal do cruzeiro, todos os documentos que restrinjam ou recusem o curso legal do cruzeiro, enfim todas as obrigações que restrinjam ou recusem o curso legal do cruzeiro, inclusive quando restrinjam ou recusem esse curso mediante a estipulaçāo de pagamento em ouro ou em moeda estrangeira. Em outras palavras, o artigo não declara nulos todos os contratos, títulos, documentos $e$ obrigaçōes, mas tão-somente aqueles que restrinjam ou recusem o curso legal do cruzeiro" (Cambial em moeda estrangeira, São Paulo, Revista dos Tribunais, 1978, p. 38).

Estabelecendo, outrossim, o exato alcance do diploma citado, pontifica:

"Esse decreto-lei, na verdade, não vai além de seu explícito fundamento, estabelecendo assim que são nulas tão-somente as obrigações de efetivo pagamento em moeda estrangeira (deixando de lado o pagamento em ouro, não só porque regulamentaçāo específica o torna inexeqüivel, mas principalmente porque, 
desvirtuando-se, ele é impossivel na cambial), e não todas as obrigações que contêm designação de pagamento em moeda estrangeira, porque essa simples designação, sem cláusula de efetivo pagamento, não tira o título do império da moeda nacional, dotada por lei de pleno poder liberatório" (Ibid., p. 48-49).

Concluindo, apresenta o seu incisivo posicionamento a respeito, dizendo que a

"legislação brasileira sobre a questão passou a consistir na proibição genérica da estipulação de pagamento efetivo em moeda estrangeira, permitida portanto a simples mençâo de pagamento nessa moeda, sujeita ao poder liberatório da moeda nacional" (Ibid., p. 53).

26. Distinguindo, outrossim, as duas funções que a referência à moeda estrangeira exerce em tema de obrigaçōes, esclarece, com precisão, Orlando Gomes que:

"Em tese, porém, a dívida pecuniária pode ter como objeto moeda estrangeira. Se estipulado que o pagamento deve ser efetuado em determinada espécie monetária, como, por exemplo, dólares, francos ou escudos, $\boldsymbol{b}$ devedor somente se libera se pagar na moeda convencionada. Mas, em outros casos, a referência contratual à moeda estrangeira faz-se apenas com o objetivo de estabelecer determinada base para o cálculo do valor da dívida (indexação). Nesse caso, a dívida pode ser paga em moeda nacional, feita a necessária conversão, que, segundo a opinião dominante, deve ser realizada pela taxa do câmbio vigente no momento em que o pagamento se efetua, e, nāo, como outros pensam, no dia do vencimento" (Obrigaçōes, $4^{\mathrm{a}} \mathrm{ed}$., Rio, Forense, 1976, p. 60). 
27. Mostra-se, portanto, plenamente adequada a indexação pelo modo exposto, tornando-se exigível o respectivo quantum, pelas vias processuais competentes, caso qualquer das partes venha a escusar-se ao implemento de suas obrigações, em especial o devedor, ou eventual sucessor.

28. É que, assentado o índice, passa o credor a contar com a correção monetária, cabendo, pois, ao devedor satisfazer os pagamentos com fulcro nas variações operadas na moeda adotada.

Eventual resistência atestaria absoluta inconformidade de sua conduta com os ditames maiores que presidem a contratação privada, em particular com o princípio da boa-fé. De fato, após haver aceito a indexação, o recuo do devedor significaria esquiva a pagamento contratado, com sensíveis prejuízos para o credor. De outro lado, em função da inflação constatada, seu patrimônio se locupletaria com os ingressos que não realizasse em prol do credor e, ademais, sem justo título.

29. Cercar-se-ia, assim, sua atuação de plena desobediência aos padrões éticos exigidos pelo referido princípio, que impõe a cada parte que desenvolva suas ações para a satisfação dos interesses da outra, a fim de que o contrato cumpra as próprias finalidades; vale dizer, que se realizem os objetivos econômicos postos pelos interessados no negócio efetivado.

Aliás, é de meridiana clareza a correlação referida, na exata medida do conhecimento de que contrato é mecanismo jurídico de consecução de interesses econômicos, exercendo a função social de circulação de riquezas para a realização dos vários interesses suscetíveis de regulação pela vontade individual.

30. Ora, no centro de sua construção teórica está o princípio da boa-fé, que impera em toda a sua extensão, diante da influência que a moral exerce no âmbito do direito contratual, como universalmente se reconhece (v. Georges Ripert, ob. cit., p. 79 e ss.; René Savatier, ob. cit., p. 140 e ss.; Luiz DiezPicazo, ob. cit., p. 45 e ss; e inúmeros outros autores). 
31. Escrevemos, a propósito, que:

"Presente tanto na formação, na conclusão e na execução, o princípio impregna de moralidade a atividade negocial, na defesa de valores básicos da convivência humana $e$ de direitos insitos na personalidade. Com isso, o comportamento da parte, em todos os diferentes momentos do relacionamento, desde a aproximação à consecução de todas as obrigações, deve estar imbuído de espírito de lealdade, respeitando cada um o outro contratante e procurando, com a sua ação, corresponder às expectativas e aos interesses do outro contratante. Fidelidade à palavra, lealdade no tratamento e cumprimento adequado das obrigações, consoante padrōes normais à contratação a que se vincula, sāo, pois, noçōes componentes do princípio em questāo, que encontra, ademais, consagração legislativa em vários pontos das codificações, inclusive a nossa, que em diferentes situações protege especialmente a parte que, em sua ação, o obedece (como, dentre outros, nos casos de aquisição de boa-fé, atuaçāo por outrem de boa-fé, posse de boa-fé)" (Direito dos contratos e dos atos...ob. cit., p. 39).

32. De fato, é essencial a boa-fé na formação e na execução dos contratos, pois produz inúmeros reflexos no plano jurídico e, como diz Vicente Ráo:

"exerce, nos atos jurídicos, funçōes e efeitos de suprimento de incapacidade, saneamento de atos nulos ou anuláveis, de aquisição de direitos e de um modo geral, de proteção de interesses legítimos ou de direitos de terceiros" (Ato jurídico, São Paulo, Saraiva, 1981, p. 228). 
33. Salienta Diez-Picazo que:

"El orden economico debe estar informado de acuerdo con los postulados del principio general de la buena fé. Con ello se pretende impregnar de un contenido ético impuesto por las concepciones morales imperantes a los escuetos arreglos de intereses privados.

La buena fé consiste, en primer lugar, en la lealtad en los tratos y en la fidelidad a la palabra dada. La buena fé, sin embargo, posee una eficacia mucho más amplia. Significa que los derechos subjetivos de naturaleza económica tienen que ser ejercitados de conformidad con la buena fé y que las obligaciones deben también de buena fé ser cumplidas" (ob. cit., p. 45).

34. Essa é, aliás, a posição da doutrina universal, que na jurisprudência também tem obtido sagração, diante da justiça necessária no plano da contratação privada (v. dentre outros autores, Boris Starck, Droit civil: obligations, Paris, Librairies Techniques, 1972, p. 562).

35. Com precisão, escreve Jacques Ghestin,

"La loyauté dans les contrats est le complément nécessaire de la justice contractuelle. Cette obligation de loyauté imprègne d'ailleurs le droit tout entier au travers du principe moral de bonne foi. Celle-ci, en effet, est synonyme de sincerité, de franchise et plus largement de loyauté. Elle s'oppose à la mauvaise foi, le dol, la tromperie ou la fraude" (ob. cit., p. 141).

Ressaltando, depois, a explícita previsão da boa-fé na codificação francesa quanto à execução dos contratos, enfatiza que:

"La responsabilité, au cas d'inexécution d'une obligation contractuelle sera plus ou moins lourde selon la bonne foi du débiteur" (Ibidem). 
36. Nesse sentido, aliás, já sentenciava Ripert:

"la bonne foi est l'un des moyens utilisés par le législateur et les tribunaux pour faire pénétrer la règle morale dans le droit positive" (ob. cit., $\mathrm{n}^{\mathrm{o}}$ 157),

deixando claro que é fator decisivo no debate de litígios e de discussões de cunho jurídico.

37. Pontofinalizando, temos a assentar que:

a. é perfeitamente válida a cláusula de indexação pela variação de moeda estrangeira (dólar turismo ou outra);

b. somente encontra obstáculo jurídico quando lei explícita a proíba, como na área do inquilinato;

c. uma vez estipulada, deve ser respeitada pelo devedor, em razão da boa-fé que preside as negociações, sob pena de sancionamentos próprios, detectáveis à luz do caso concreto. 